\title{
Effect of different nursing educational methods on the quality of bowel cleanliness for patients undergoing colonoscopy
}

\author{
Wafaa R. Ahmed ${ }^{* 1}$, Mimi M. Makkawy ${ }^{1}$, Zain Al-Abdeen A. Sayed ${ }^{2}$, Sahra Z. Azer ${ }^{1}$ \\ ${ }^{1}$ Faculty of Nursing, Assiut University, Assiut, Egypt \\ ${ }^{2}$ Faculty of Medicine, Assiut University, Assiut, Egypt
}

Received: November 4, 2015

DOI: $10.5430 /$ jnep.v6n7p54
Accepted: December 27, $2015 \quad$ Online Published: February 17, 2016

URL: http://dx.doi.org/10.5430/jnep.v6n7p54

\begin{abstract}
Background: Colonoscopy is an endoscopic examination of the large intestine and the distal part of the small intestine with a fiber optic camera on a flexible tube passed through the anus. An estimated 11-14 million colonoscopies are performed in the United States annually. The aim of the study was to evaluate the effect of different nursing educational methods (video, educational booklet, both booklet \& video and routine nursing instructions) on the quality of bowel cleanliness for patients undergoing colonoscopy.

Methods: Research design: A quiz-experimental research design was being utilized. Subjects and methods: A convenience sample of 120 adult patients was divided into four groups, 30 patients for each. Patients' mean age was (42.6 \pm 12.8$)$ years from both sexes. The study was conducted at Internal medicine, General surgery departments and Gastrointestinal Endoscopy Center at Assiut University Hospitals. Tools: Two tools were being utilized: patient assessment sheet and colonoscopy preparation educational methods.

Results: More than half of the patients (53.3\%) in routine nursing instructions group have a bad level of bowel cleanliness with mean score of Boston bowel preparation scale (BBPS) of $2.7 \pm 2.4$, more than two thirds of patients (70\%) at preparation video group have a fair level with mean score of BBPS of $4.7 \pm 2.2$, while more than half of patients in booklet and both video \& booklet groups $(53.3 \% \& 56.7 \%)$ have an excellent level with mean score of BBPS of $5.9 \pm 2.4 \& 6.7 \pm 1.2$, respectively.

Conclusions: More than half of the patients at educational booklet and both video \& booklet groups have an excellent level, more than two thirds of patients at preparation video group have a fair level, while more than half of the patients in routine nursing instructions group have a bad level of bowel cleanliness. Recommendation: Relevant written and visual information facilitate educating patients about proper preparation of the bowel before colonoscopy, signs and symptoms of the potential complications and the importance of seeking rapid medical advice after colonoscopy.
\end{abstract}

Key Words: Nursing, Quality, Bowel, Cleanliness, Colonoscopy

\section{INTRODUCTION}

Colonoscopy is a common procedure in medical practice for a variety of gastrointestinal indications. It is widely used in the United States, especially since 2001, when medicare expanded its coverage for screening for colorectal cancer to include colonoscopy. ${ }^{[1]}$ An estimated 11-14 million colonoscopies are performed in the United States annually. ${ }^{[2]}$

Colonoscopy is a procedure that uses a long, flexible, nar-

*Correspondence: Wafaa R. Ahmed; Email: Wafaa_Ramadan27@yahoo.com; Address: Faculty of Nursing, Assiut University, Assiut, Egypt. 
row tube with a light and tiny camera at one end, called a colonoscope ${ }^{[3]}$ Indications include investigation of overt or occult bleeding, in the setting of gastrointestinal bleeding of undetermined origin, colonoscopy may be both diagnostic and therapeutic. ${ }^{[4]}$

There are few contraindications to endoscopic examination of the lower GI tract as a perforated viscus, severe acute diverticulitis, or fulminent colitis. Relative contraindications were uncooperative patients, have poor or inadequate bowel preparations, or have poor general medical conditions such as a recent myocardial infarction or pulmonary embolism. ${ }^{[5]}$

It is important that patients are educated and engaged in the colonoscopy preparations process, and it has been shown that effective education significantly improves the quality of bowel preparation. Patient counselling along with written instructions that are simple and easy to follow and in their native language should be provided to patients, and patient education may improve with the use of visual aids. Recently, educational booklets were shown to improve quality of bowel preparation. ${ }^{[6]}$

The success of colonoscopy depends on how well the colon is prepared. Adequate colon cleansing provides optimal visualization and decreases the time needed for the procedure. Cleansing of the colon can be accomplished in various ways. The physician may prescribe a laxative for two nights before the examination and a fleet's or saline enema until the return is clear at the morning of the test. The patient maintains a clear liquid diet starting at the day before the procedure. ${ }^{[7]}$

Several instruments have been developed to evaluate the quality of bowel preparation. Bowel preparation scales (BPS) can be used to evaluate the cleanliness of the gut, and also to document the superiority of a preparation regime against another. The Boston bowel preparation scale was developed recently, and is a 9-point scale designed to evaluate bowel preparation after all cleansing has been completed by the endoscopist. ${ }^{[8]}$

Boston bowel preparation scale (BBPS) was developed by the section of gastroenterology at Boston Medical Center (BMC) to provide a much needed standard for rating the quality of bowel preparation for colonoscopy. This tool published in October 2010 in the Journal of Gastrointestinal Endoscopy shows the level of accuracy and could become a standard tool for cleaning international index colon during colonoscopy. ${ }^{[9]}$

Complications during and after the procedure can include cardiac dysrhysmias, respiratory depression, abdominal pain and discomfort, Gas explosion, circulatory overload or hypotension resulting from over hydration or under hydration during bowel preparation. Also, bleeding and colonic perforation may be occurred due to mechanical forces against the bowel wall. ${ }^{[10]}$

Selecting a teaching method requires the nurse to conduct an assessment of each learner's needs, readiness to learn, and learning style as well as to determine with the patient the behavioral objectives to be accomplished. There is no one right method, because the best approach depends on many variables such as the audience, the content to be taught, and the setting in which learning and teaching takes place. Also, considerations must be given to available resources such as time, money, place, and materials to support teaching and learning activities. ${ }^{[1]]}$

Videos are an option for distributing patient education information. Videos about various medical topics are produced and electronically distributed by pharmaceutical companies, hospitals, and office practices. This method is especially helpful for demonstrating skills because the video can be replayed and stopped. This method is effective because it takes advantages of more than one route for imparting information. It is also independent of reading level. It is cheapest to lend the DVD to the patient for home viewing, with subsequent return to the practice when finished. ${ }^{[12]}$

The aim of the study was to evaluate the effect of different nursing educational methods (video, educational booklet, both booklet \& video and routine nursing instructions) on the quality of bowel cleanliness for patients undergoing colonoscopy.

\subsection{Hypothesis}

To fulfil the aim of the study the following research hypothesis was formulated:

(1) The mean score level of Boston bowel preparation scale in patients who receives video will be higher than that score in patients who receives routine care.

(2) The mean score level of Boston bowel preparation scale in patients who receives educational booklet will be higher than that score in patients who receives video.

(3) The mean score level of Boston bowel preparation scale in patients who receives both video and booklet will be higher than that score in patients who receives routine care.

(4) The incidence of colonoscopy problems and complications in patients who receives both video and educational booklet will be less than patients who receives routine care. 


\subsection{Significance of the study}

In 2014, 540 colonoscopic procedures were performed in the Gastrointestinal Endoscopy Center at Assiut university hospital (Assiut hospital statistical records, 2014), ${ }^{[13]}$ many cases of them were canceled and repeated the procedure due to difficult visualization of the colon and inadequate bowel preparations; this can lead to increase the economic impact by prolonging the procedure time and the hospital stay. Patients undergoing colonoscopy needed special nursing preparations to improve the quality of bowel cleanliness and minimize the incidence of risks and complications.

\section{MethodS}

\subsection{Research design}

Quiz-experimental research design was being utilized in this study.

\subsection{Study variables}

The independent variable in this study was the nursing educational methods (routine nursing instructions, an educational booklet, a colonoscopy preparation video and both booklet $\&$ video). While the dependent variable was the quality of bowel preparation.

\subsection{Setting}

The study was conducted at Gastrointestinal Endoscopy Center, Internal Medicine and General Surgery Departments at Assiut University Hospital.

\subsection{Patients}

A convenience sample of 120 adult patients undergoing colonoscopy procedure was divided into four groups: 30 patients for each group. The first group (Control group) was received routine nursing instructions; the second group was received nursing educational booklet only; the third group was received a colonoscopy preparation video only; and the last group was received both the video and the booklet. To ensure the randomization, the odd numbers were received routine nursing instructions and the colonoscopy preparation video only, while the double numbers were received nursing educational booklet only and both the video and the booklet.

\subsection{Inclusion criteria}

Study group was selected according to the following criteria: Adult conscious patients undergoing colonoscopy, both sexes (male and female), age range between (18-65 years), and ability to complete the participation in the research regardless the educational level.

\subsection{Tools of data collection}

Two tools were being utilized for data collections:

\subsubsection{Tool I: Patient assessment sheet}

It was developed by the researcher and consisted of three main parts:

Part I: Pre-colonoscopy assessment It included: Socio demographic data of study sample (120 patients) such as: Patient's name, age, gender, marital status, occupation, level of education, residence, general assessment about medical diagnosis, family history, and reason for colonoscopy.

Part II: BBPS The BBPS was developed by the section of gastroenterology at BMC, published in October 2010 in the Journal of Gastrointestinal Endoscopy to provide a muchneeded standard for assessing the quality of bowel preparation for colonoscopy. It showed the level of accuracy and could become a standard tool for cleaning international index colon during colonoscopy. The maximum BBPS score for a perfectly clean colon without any residual liquid is 9 and the minimum BBPS score for an unprepared colon is 0 (see Figure 1).

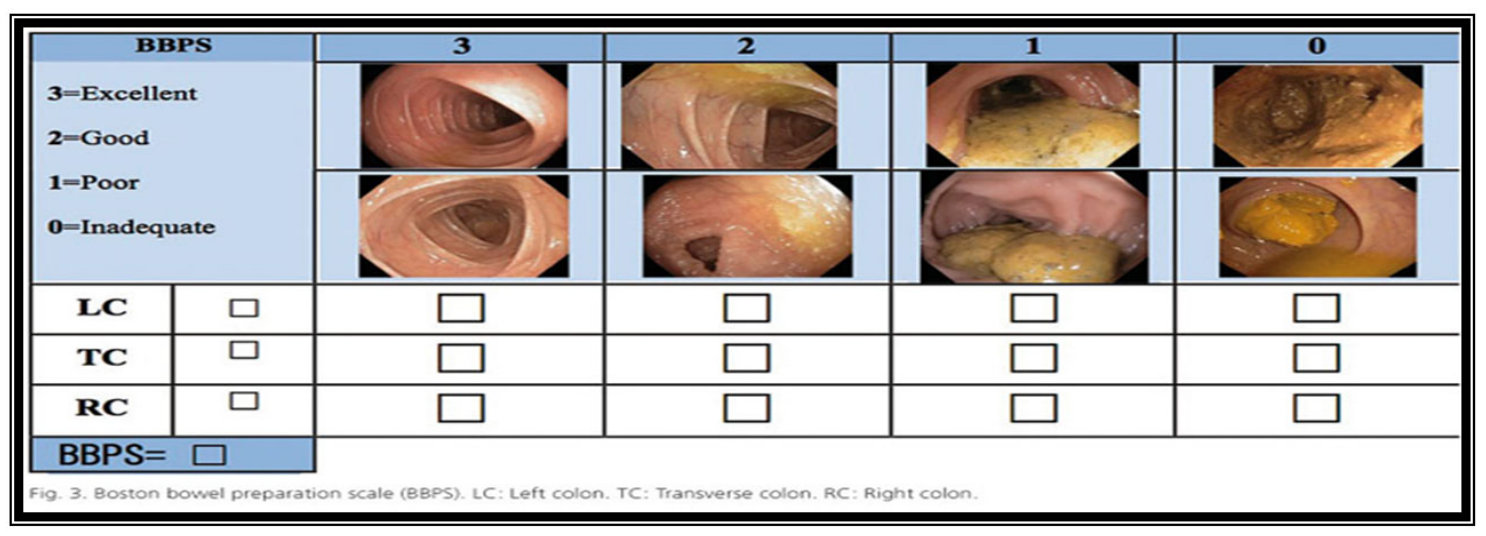

Figure 1. Boston Bowel Preparation Scale. Adopted from Zúñiga et al. (2012) LC: Left colon; TC: Transverse colon; RC: Right colon. 
Scoring system: The maximum BBPS score for a perfectly clean colon without any residual liquid is 9 and the minimum BBPS score for an unprepared colon is 0. Excellent (more than 7 degrees), Fair (4-6 degrees) and Bad (less than 3 degrees).

Part III: Assessment of post colonoscopy problems and complications This part was utilized to assess colonoscopy problems such as difficult visualization of the colon, prolonged procedure time ( $>1 \mathrm{hr}$.), and cancelled and repeated colonoscopy, and post colonoscopy complications such as abdominal pain, abdominal distension, hypoxia, chest pain, tachycardia, cardiac dysrhythmias, respiratory depression, hypertension, hypotension, bleeding, perforation, gas explosion, vomiting, fever or postpolypectomy electrocoagulation syndrome.

\subsubsection{Tool II: Colonoscopy preparation educational meth- ods}

It consisted of three main parts:

Part I: Colonoscopy preparation video A ten minutes colonoscopy educational video was presented by Dr. Ahmed El-fadly, consultant of gastroenterology at Mubarak hospital at Al-Kawait country published at YouTube in November 2012. This video contains oral presentation about anatomy of the colon, definition and importance of colonoscopy, brief explanation about preparation before colonoscopy, what will happen during colonoscopy, colonoscopy problems and complications and what will happen post colonoscopy?

Part II: Nursing educational booklet This tool was developed by the researcher based on the review of the relevant literatures to provide colonoscopy patients with needed instructions to obtain accurate bowel preparation before colonoscopy and to minimize the incidence of colonoscopy problems and complications. The nursing educational booklet included anatomy and function of the colon, definition of colonoscopy, why it is important to get cleaned colon pre colonoscopy? colon preparation before colonoscopy, permitted and avoided foods and drinks, what will happen during colonoscopy? warning signs post colonoscopy and what will happen post colonoscopy?

Part III: Both nursing educational booklet $\&$ video In this part the researcher used both nursing educational booklet and colonoscopy preparation video together to provide patients with needed instructions to obtain accurate bowel preparation before colonoscopy and to minimize the incidence of colonoscopy problems and complications.

Routine nursing instructions: Nurses at general surgery and internal medicine departments instruct patients precolonoscopy to increase fluid intake and fast from midnight Published by Sciedu Press at the previous day of colonoscopy. There wasn't any participation from the researcher for educating patients for colon preparation before colonoscopy.

\subsection{Administrative approval}

An official permission was obtained from the head of the gastrointestinal endoscopy center, internal medicine and general surgery departments at Assiut university hospital to conduct the study.

The first tool (patient assessment sheet) was developed by the researcher after extensive review of the relevant literature. The tool was tested for content validity by 5 experts of academic medical and nursing staff at Assiut University. Modifications were done accordingly, and then the tool was designed in its final format and tested for reliability by using internal consistency for the tools measured using Cronbach test, the tools proved to be reliable (0.73).

\subsection{Ethical consideration}

An oral permission for voluntary participation was obtained from patients and the nature and purpose of the study was explained. The researcher initially introduced himself to all patients and they were assured that the collected data would be absolutely confidential. Patients were informed that participation is voluntary and that they could withdraw at any time of the study. Confidentiality of the patient's data was ascertained. Confidentiality and anonymity were assured. Patients' names were coded for data entry so that their names could not be identified.

\subsection{Pilot study}

A pilot study was conducted on $10 \%$ of sample (12 patients) in a selected setting to evaluate the applicability \& clarity of the tools. According to this pilot study, the required modifications were made. Those patients who were involved in the pilot study were not included in the study sample. The researcher met every patient and take present and past history pre-colonoscopy using Tool I (part I). Colonoscopy preparation video and nursing educational booklet were used to provide patient with needed instructions for proper bowel preparation before colonoscopy Tool II (part I, II \& III). Assess the quality of bowel cleanliness intra colonoscopy Tool I (part II) and assess colonoscopy problems and complications post colonoscopy using Tool I (part III).

\subsection{Data collection}

The data collection was done through the following phases:

\subsubsection{Assessment phase}

The researcher interviewed the patients who were requested for colonoscopy at general surgery and internal medicine 
departments and get their oral consent to participate in the study. Categorization of patients to four groups (30 patients for each) were done. To ensure the randomization, the odd numbers were received routine nursing instructions and the colonoscopy preparation video only, while the double numbers were received nursing educational booklet only and both the video and the booklet for example, the first patient received routine nursing instructions, the second patient received nursing educational booklet, the third patient received colonoscopy preparation video, and the fourth patient received both educational booklet and video. Patient assessment sheet (tool I, part I) was applied which is concerned by patient's sociodemographic data (patient's name, age, gender, marital status, occupation, level of education, and residence) and general assessment about medical diagnosis, family history, and reason for colonoscopy. Patient assessment sheet (tool I, part I) was applied on every patient individually at the four groups.

\subsubsection{Implementation phase}

The first group of patients (30 patients) received routine nursing instructions (there wasn't any participation from the researcher for educating patient for colon preparation before colonoscopy and they considered as a control group).

Colonoscopy preparation educational method (Tool II) was applied; the second group of patients received nursing educational booklet (Tool II part II); each patient received the instructions in one session one to two days before colonoscopy according to policy of the center. Each session takes 15-30 minutes. After each session there was 5-10 minutes for discussion and gave feedback. Reinforcement of teaching was performed according to patient's needs to ensure their understanding. Each patient in the group obtained a copy of the teaching booklet; the researcher used pictures for illustration, diagram to educate the patient.

The third group of patients received colonoscopy preparation video (Tool II part I) by laptop of the researcher. Patients who have smart phones or laptop can obtain a copy from the video. The video takes 10 minutes after showing the video there was 5 - 10 minutes for discussion and gave feedback.

The fourth group of patient received both educational video and booklet (Tool II part III) by laptop of the researcher and educational booklet together. Each patient in the group can obtain a copy from the booklet and video. After explaining the instructions guided by the pictures at the educational booklet, video can be showed to enforce the information. There was 5-10 minutes for discussion and gave feedback.

\subsubsection{Evaluation phase}

At the day of colonoscopy the researcher met every patient of the four group at the gastrointestinal endoscopy center and the researcher assessed the quality of bowel preparation using Boston bowel preparation scale (Tool I part II) intracolonoscopy. Each patient obtained a score from 9 to reflect the effect of the educational method on the quality of bowel preparation.

The researcher assessed the problems and complications (Tool II part III) that happened during colonoscopy procedure and following up the patient for three days after colonoscopy to assess the complications that may happen at their units (general surgery or internal medicine departments).

\subsection{Statistical design}

Data collected and analysed by computer program SPSS ver. 20 Chicago, USA. Data expressed as mean, Standard Deviation, number, and Percentage. Using $T$ test to determine significant for numeric variable. Using Chi square to determine significant for non-parametric variable. (* Statistical significant difference $(p \leq .05)$ and ns $(p>.05)$ was considered as non significant).

\subsection{Limitation of the study}

(1) The preparation period of patient before colonoscopy not enough because Gastro Endoscopy unit specified the procedure time from 24-48 hrs after receiving colonoscopy request from medical or surgical units at Assiut university hospital.

(2) The level of literacy in patient population limits their ability to access or benefit from some parts in the educational booklet because of lack in their reading abilities.

(3) The majority of patients who received colonoscopy preparation video haven't laptop or smart phones so the patients received the video only once using the researcher's laptop.

\section{RESUlts}

Table 1 illustrated that, more than half of patients in routine, video and both booklet \& video were males, while more than half of patients in booklet group were females. More than one third of patients at routine instructions, educational booklet, and preparation video groups $(46.7 \%, 43.3 \%$, and $36.7 \%$ ) respectively and more than half of patients at both video \& booklet group $(65.7 \%)$ their ages ranging between (30-50) years.

Regarding the patients' marital status, the majority of patients in the four study groups were married. Regarding education, $36.7 \%$ and $30 \%$ of routine nursing instruction groups 
and nursing educational booklet group of patients have secondary education level, while $46.7 \%, 36.7 \%$ of preparation video and both video and booklet groups of patients were illiterate. Regarding occupation, more than one third of patients in the routine instructions, educational booklet and preparation video groups of patients were housewives, while more than one third of patients at both video and booklet group are employees. Regarding residence the majority of patients in all four study groups were lived in rural areas with $80 \%, 70 \%, 86.75 \%$ and $66.7 \%$ for routine instructions, educational booklet, preparation video and both video and booklet groups respectively. Finally, the table shows that there is no statistical significant difference between the four study groups regarding sociodemographic characteristics of patients undergoing colonoscopy.

Table 1. Frequency distribution of socio-demographic characteristics of four study groups of patients undergoing colonoscopy (Pre-colonoscopy)

\begin{tabular}{|c|c|c|c|c|c|c|c|c|c|c|}
\hline \multirow[t]{2}{*}{ Variables } & \multicolumn{2}{|c|}{$\begin{array}{l}\text { Routine } \\
\text { instructions } \\
(\mathbf{n}=\mathbf{3 0})\end{array}$} & \multicolumn{2}{|c|}{$\begin{array}{l}\text { Educational } \\
\text { booklet } \\
(n=30)\end{array}$} & \multicolumn{2}{|c|}{$\begin{array}{l}\text { Preparation } \\
\text { video } \\
(\mathbf{n}=\mathbf{3 0})\end{array}$} & \multicolumn{2}{|c|}{$\begin{array}{l}\text { Both video and } \\
\text { booklet } \\
(n=30)\end{array}$} & \multirow[t]{2}{*}{$\chi^{2}$} & \multirow[t]{2}{*}{$p$} \\
\hline & No. & $\%$ & No. & $\%$ & No. & $\%$ & No. & $\%$ & & \\
\hline \multicolumn{11}{|l|}{ Age } \\
\hline 18-30 years & 9 & 30.0 & 8 & 26.7 & 8 & 26.7 & 5 & 16.7 & & \\
\hline $30-50$ years & 14 & 46.7 & 13 & 43.3 & 11 & 36.7 & 17 & 56.7 & 3.56 & $.735 \mathrm{~ns}$ \\
\hline$>50$ years & 7 & 23.3 & 9 & 30.0 & 11 & 36.7 & 8 & 26.7 & & \\
\hline Mean \pm SD & \multicolumn{2}{|c|}{$40.8 \pm 13.3$} & \multicolumn{2}{|c|}{$42.2 \pm 13.1$} & \multicolumn{2}{|c|}{$45.1 \pm 12.8$} & \multicolumn{2}{|c|}{$42.0 \pm 12.0$} & $F=0.62$ & $.601 \mathrm{~ns}$ \\
\hline Total mean \pm SD & \multicolumn{4}{|c|}{$42.6 \pm 12.8$} & & & & & & \\
\hline \multicolumn{11}{|l|}{ Gender } \\
\hline Male & 16 & 53.3 & 14 & 46.7 & 16 & 53.3 & 18 & 60.0 & \multirow{2}{*}{1.07} & \multirow{2}{*}{$.784 \mathrm{~ns}$} \\
\hline Female & 14 & 46.7 & 16 & 53.3 & 14 & 46.7 & 12 & 40.0 & & \\
\hline \multicolumn{11}{|l|}{ Marital status } \\
\hline Single & 4 & 13.3 & 4 & 13.3 & 4 & 13.3 & 3 & 10.0 & \multirow{3}{*}{5.30} & \multirow{3}{*}{$.507 \mathrm{~ns}$} \\
\hline Married & 21 & 70.0 & 23 & 76.7 & 17 & 56.7 & 23 & 76.7 & & \\
\hline Widow/widower & 5 & 16.7 & 3 & 10.0 & 9 & 30.0 & 4 & 13.3 & & \\
\hline \multicolumn{11}{|l|}{ Level of education } \\
\hline High education & 2 & 6.7 & 5 & 16.7 & 2 & 6.7 & 6 & 20.0 & \multirow{5}{*}{8.56} & \multirow{5}{*}{$.740 \mathrm{~ns}$} \\
\hline Secondary education & 11 & 36.7 & 9 & 30.0 & 10 & 33.3 & 8 & 26.7 & & \\
\hline Basic education & 7 & 23.3 & 7 & 23.3 & 4 & 13.3 & 4 & 13.3 & & \\
\hline Read and write & 1 & 3.3 & 1 & 3.3 & - & - & 1 & 3.3 & & \\
\hline Illiterate & 9 & 30.0 & 8 & 26.7 & 14 & 46.7 & 11 & 36.7 & & \\
\hline \multicolumn{11}{|l|}{ Occupation } \\
\hline Employee & 7 & 23.3 & 7 & 23.3 & 6 & 20.0 & 11 & 36.7 & \multirow{5}{*}{11.27} & \multirow{5}{*}{$.506 \mathrm{~ns}$} \\
\hline Farmer & 3 & 10.0 & 7 & 23.3 & 6 & 20.0 & 4 & 13.3 & & \\
\hline Housewife & 12 & 40.0 & 11 & 36.7 & 12 & 40.0 & 8 & 26.7 & & \\
\hline Student & - & - & 2 & 6.7 & - & - & 2 & 6.7 & & \\
\hline Skilled worker & 8 & 26.7 & 3 & 10.0 & 6 & 20.0 & 5 & 16.7 & & \\
\hline \multicolumn{11}{|l|}{ Residence } \\
\hline Urban & 6 & 20.0 & 9 & 30.0 & 4 & 13.3 & 10 & 33.3 & \multirow{2}{*}{4.14} & \multirow{2}{*}{$.247 \mathrm{~ns}$} \\
\hline Rural & 24 & 80.0 & 21 & 70.0 & 26 & 86.7 & 20 & 66.7 & & \\
\hline
\end{tabular}

Table 2 shows that in one hand more than one quarter of patients in routine instruction and preparation video group were diagnosed as ulcerative colitis $(23.3 \%, 26.8 \%)$, and iron deficiency anemia $(26.7 \%, 33.3 \%)$ respectively. On the other hand more than one quarter of patients in educational booklet and both video \& booklet groups were diagnosed as ulcerative colitis and colorectal cancer with $(23.3 \%)$ for each diagnosis. Also, the majority of patient in all four study groups haven't family history of the diagnosis. Table 2 shows that there is no statistical significant difference between the four study groups regarding medical diagnosis and family history of the diagnosis of patients undergoing colonoscopy.

Table 3 mentions that, more than one third of patients as in routine nursing instructions, pre colonoscopy preparation video and both video and booklet group. More than half of patients (as in nursing educational booklet group) (33.3\%, $46.7 \%, 43.3 \%$ and $60 \%$ ) respectively were suffering from rectal bleeding. Also, one third of the patients (as in routine nursing instructions, nursing educational booklet and pre colonoscopy preparation video groups) and one half of pa- 
tients as in both video and booklet group perform therapeutic four study groups regarding reasons of colonoscopy. colonoscopy and tissue biopsies were taken. The table shows that there is no statistical significant difference between the

Table 2. Frequency distribution of medical diagnosis and family history of four study groups of patients undergoing colonoscopy (Pre-colonoscopy)

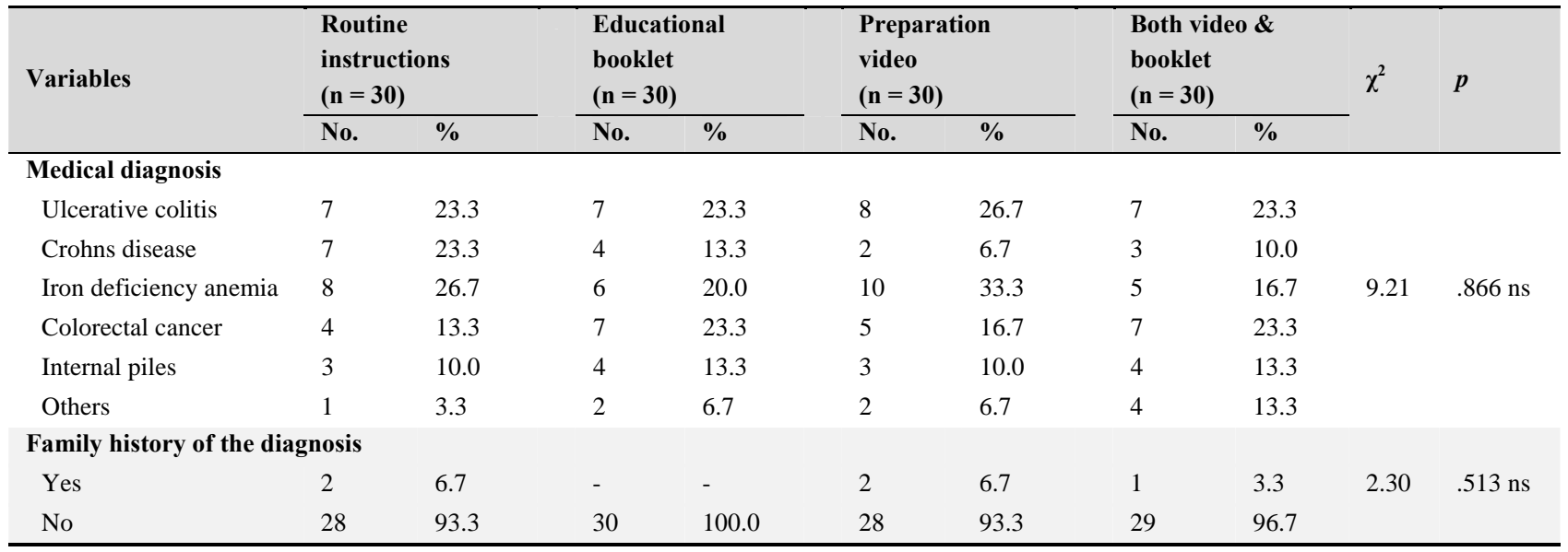

Table 3. Frequency distribution of reason of colonoscopy of four study groups of patients undergoing colonoscopy (Precolonoscopy)

\begin{tabular}{|c|c|c|c|c|c|c|c|c|c|c|}
\hline \multirow[t]{2}{*}{ Variables } & \multicolumn{2}{|c|}{$\begin{array}{l}\text { Routine } \\
\text { instructions } \\
(\mathbf{n}=\mathbf{3 0})\end{array}$} & \multicolumn{2}{|c|}{$\begin{array}{l}\text { Educational } \\
\text { booklet } \\
(n=30)\end{array}$} & \multicolumn{2}{|c|}{$\begin{array}{l}\text { Prepara- } \\
\text { tion video } \\
(\mathbf{n}=\mathbf{3 0})\end{array}$} & \multicolumn{2}{|c|}{$\begin{array}{l}\text { Both video } \\
\text { and booklet } \\
(\mathrm{n}=\mathbf{3 0})\end{array}$} & \multirow[t]{2}{*}{$\chi^{2}$} & \multirow[t]{2}{*}{$p$} \\
\hline & No. & $\%$ & No. & $\%$ & No. & $\%$ & No. & $\%$ & & \\
\hline \multicolumn{11}{|l|}{ Diagnostic } \\
\hline Rectal bleeding & 10 & 33.3 & 18 & 60.0 & 14 & 46.7 & 13 & 43.3 & & \\
\hline Change in bowel habits (chronic diarrhea) & 3 & 10.0 & 4 & 13.3 & 4 & 13.3 & 2 & 6.7 & & \\
\hline Rectal bleeding \& change in bowel habits & 2 & 6.7 & 1 & 3.3 & 1 & 3.3 & 2 & 6.7 & & \\
\hline Rectal bleeding \& abdominal pain & 2 & 6.7 & 1 & 3.3 & - & - & 5 & 16.7 & & \\
\hline Change in bowel habits \& un explained weight loss & 3 & 10.0 & 2 & 6.7 & 5 & 16.7 & 2 & 6.7 & & \\
\hline Change in bowel habits \& abdominal pains & 6 & 20.0 & 3 & 10.0 & 3 & 10.0 & 4 & 13.3 & & \\
\hline $\begin{array}{l}\text { Change in bowel habits \& recurrent abdominal } \\
\text { distention }\end{array}$ & 2 & 6.7 & - & - & - & - & - & - & & \\
\hline Unexplained weight loss \& abdominal pain & - & - & - & - & 2 & 6.7 & 2 & 6.7 & & \\
\hline \multicolumn{11}{|l|}{ Therapeutic } \\
\hline Polypectomy & 1 & 3.3 & 2 & 6.7 & - & - & 3 & 10.0 & \multirow{3}{*}{6.57} & \multirow{3}{*}{$.362 \mathrm{~ns}$} \\
\hline Bleeding treatment & - & - & 1 & 3.3 & 2 & 6.7 & - & - & & \\
\hline Tissue biopsy & 11 & 36.7 & 9 & 30.0 & 13 & 43.3 & 15 & 50.0 & & \\
\hline
\end{tabular}

Table 4 shows that more than half of patients in routine instructions group $(53.3 \%)$ have bad level of bowel cleanliness and mean score of BBPS was $2.7 \pm 2.4$, more than two thirds of patients at preparation video group $(70 \%)$ have fair level of bowel cleanliness and mean score of BBPS was $4.7 \pm 2.2$, also, more than half of patients at educational booklet and both video \& booklet groups (53.3\% \& 56.7\%) have excellent level of bowel cleanliness and mean score of BBPS was $5.9 \pm 2.4$ and $6.7 \pm 1.2$. As regard to Boston bowel preparation scale, there is high $(p<.001)$ statistically significant difference in the cleaning level of the colon and mean score of BBPS for the four study groups of patients undergoing colonoscopy (see Figure 2).

Table 5 illustrates that a statistical significant difference between four groups of patients undergoing colonoscopy related to difficult visualization of the colon, canceled and repeated colonoscopy, abdominal pain or discomfort and abdominal distension (bloating). While the other items as (tachycardia, cardiac dysrhythmias and hypotension) show decrease in the incidence but not reach to a statistical significant difference (see Figure 3). 
Table 4. Frequency distribution of mean score and levels of Boston bowel preparation scale of four study groups of patients undergoing colonoscopy (Intracolonoscopy)

\begin{tabular}{|c|c|c|c|c|c|c|c|c|c|c|}
\hline \multirow[t]{2}{*}{ Variables } & \multicolumn{2}{|c|}{$\begin{array}{l}\text { Routine } \\
\text { instructions } \\
(\mathbf{n}=\mathbf{3 0})\end{array}$} & \multicolumn{2}{|c|}{$\begin{array}{l}\text { Educational } \\
\text { booklet } \\
(\mathbf{n}=\mathbf{3 0})\end{array}$} & \multicolumn{2}{|c|}{$\begin{array}{l}\text { Preparation } \\
\text { video } \\
(\mathbf{n}=\mathbf{3 0})\end{array}$} & \multicolumn{2}{|c|}{$\begin{array}{l}\text { Both video \& } \\
\text { booklet } \\
(\mathrm{n}=30)\end{array}$} & \multirow[t]{2}{*}{$\chi^{2}$} & \multirow[t]{2}{*}{$p$} \\
\hline & No. & $\%$ & No. & $\%$ & No. & $\%$ & No. & $\%$ & & \\
\hline \multicolumn{11}{|l|}{ BBPS } \\
\hline Bad & 16 & 53.3 & 3 & 10.0 & 4 & 13.3 & - & - & \multirow{3}{*}{47.67} & \multirow{3}{*}{$<.001^{* *}$} \\
\hline Fair & 12 & 40.0 & 11 & 36.7 & 21 & 70.0 & 13 & 43.3 & & \\
\hline Excellent & 2 & 6.7 & 16 & 53.3 & 5 & 16.7 & 17 & 56.7 & & \\
\hline Mean \pm SD & \multicolumn{2}{|c|}{$2.7 \pm 2.4$} & \multicolumn{2}{|c|}{$5.9 \pm 2.4$} & \multicolumn{2}{|c|}{$4.7 \pm 2.2$} & \multicolumn{2}{|c|}{$6.7 \pm 1.2$} & $F=20.5$ & $<.001 * *$ \\
\hline
\end{tabular}

** Statistical significant difference

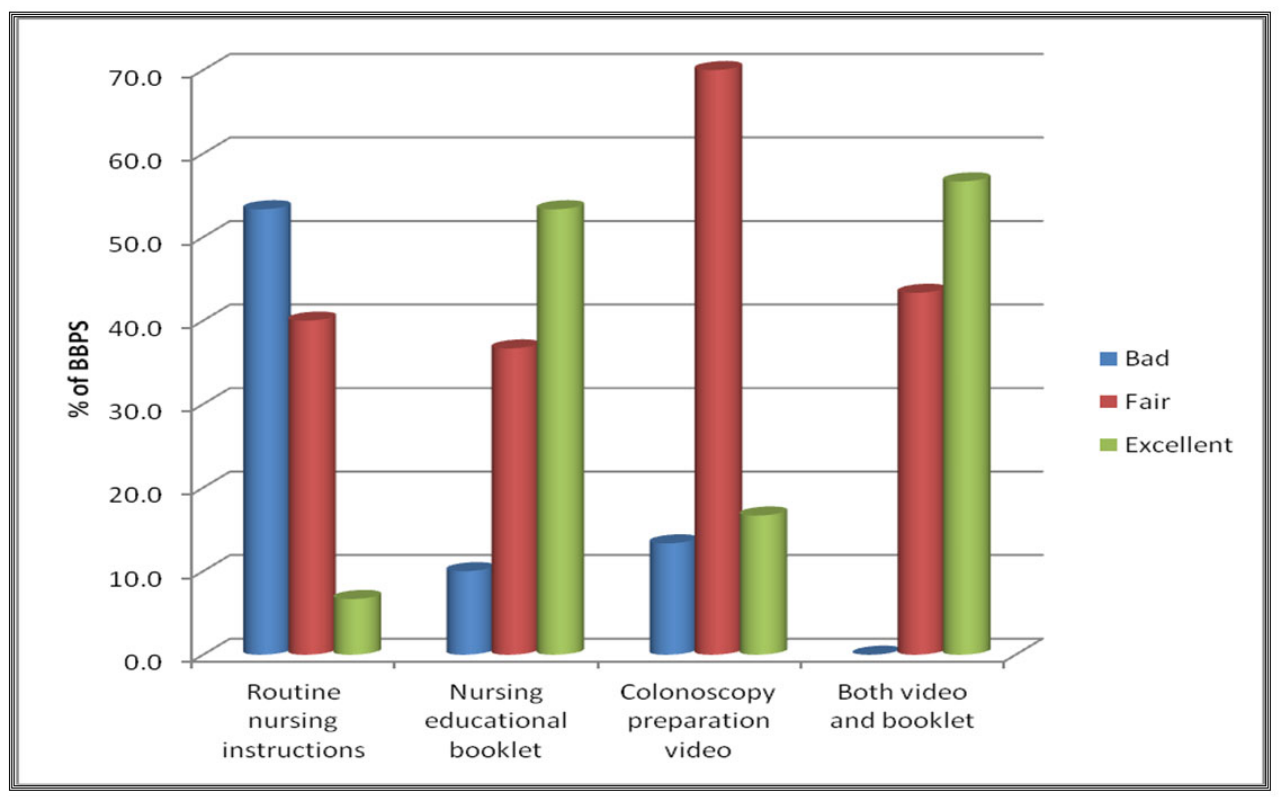

Figure 2. Frequency distribution of Boston bowel preparation scale of four study groups of patients undergoing colonoscopy (Intracolonoscopy)

Table 5. Frequency distribution of problems and complications of four study groups of patients undergoing colonoscopy (Intra and post colonoscopy)

\begin{tabular}{|c|c|c|c|c|c|c|c|c|c|c|}
\hline \multirow[t]{2}{*}{ Variables } & \multicolumn{2}{|c|}{$\begin{array}{l}\text { Routine } \\
\text { instructions } \\
(\mathbf{n}=\mathbf{3 0})\end{array}$} & \multicolumn{2}{|c|}{$\begin{array}{l}\text { Educational } \\
\text { booklet } \\
(n=30)\end{array}$} & \multicolumn{2}{|c|}{$\begin{array}{l}\text { Preparation } \\
\text { video } \\
(\mathbf{n}=\mathbf{3 0})\end{array}$} & \multicolumn{2}{|c|}{$\begin{array}{l}\text { Both video \& } \\
\text { booklet } \\
(\mathrm{n}=\mathbf{3 0})\end{array}$} & \multirow[t]{2}{*}{$\chi^{2}$} & \multirow[t]{2}{*}{$p$} \\
\hline & No. & $\%$ & No. & $\%$ & No. & $\%$ & No. & $\%$ & & \\
\hline \multicolumn{11}{|l|}{ Problems } \\
\hline Difficult visualization of the colon & 23 & 76.7 & 5 & 16.7 & 8 & 26.7 & - & - & 46.67 & $<.001^{* *}$ \\
\hline Canceled and repeated colonoscopy & 12 & 40.0 & 3 & 10.0 & 4 & 13.3 & - & - & 19.70 & $<.001^{* *}$ \\
\hline \multicolumn{11}{|l|}{ Complications } \\
\hline Abdominal pain or discomfort & 18 & 60.0 & 26 & 86.7 & 26 & 86.7 & 30 & 100 & 18.24 & $<.001^{* *}$ \\
\hline Abdominal distention (bloating) & 14 & 46.7 & 24 & 80.0 & 19 & 63.3 & 25 & 83.3 & 11.86 & $.008^{* *}$ \\
\hline Tachycardia & 4 & 13.3 & 3 & 10.0 & 3 & 10.0 & - & - & 3.93 & $.269 n s$ \\
\hline Cardiac dysrhythmias & 1 & 3.3 & - & - & - & - & - & - & 3.03 & $.388 \mathrm{~ns}$ \\
\hline Hypertension & 2 & 6.7 & 3 & 10.0 & 5 & 16.7 & 4 & 13.3 & 1.62 & $.655 \mathrm{~ns}$ \\
\hline Hypotension & 6 & 20.0 & 2 & 6.7 & 3 & 10.0 & - & - & 7.51 & $.057 \mathrm{~ns}$ \\
\hline Vomiting & - & - & 1 & 3.3 & 1 & 3.3 & 1 & 3.3 & 1.03 & $.795 \mathrm{~ns}$ \\
\hline
\end{tabular}

** Statistical significant difference 


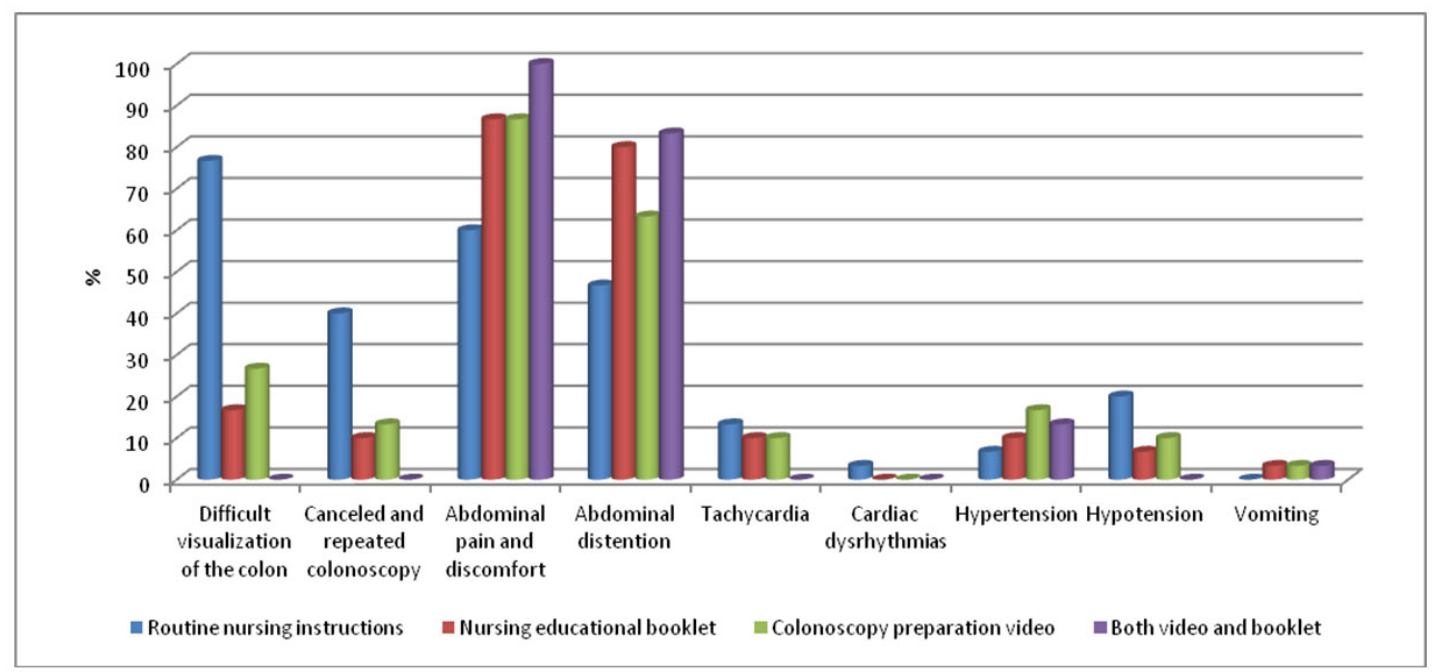

Figure 3. Frequency distribution of problems and complications of four study groups of patients undergoing colonoscopy (intra and post colonoscopy)

Table 6 illustrates that there is a highly statistical significant difference between study groups of patients undergoing colonoscopy related to difficult visualization of the colon, canceled and repeated colonoscopy, abdominal pain or dis- comfort and abdominal distension (bloating). While the other items as (tachycardia, cardiac dysrhythmias, hypertension and hypotension) show no statistical significant difference.

Table 6. Relation between problems and complications of study groups and total score categories of Boston bowel preparation scale

\begin{tabular}{|c|c|c|c|c|c|c|c|}
\hline \multirow{3}{*}{ Variables } & \multicolumn{6}{|c|}{ BBPS } & \multirow{3}{*}{$p$} \\
\hline & \multicolumn{2}{|l|}{ Bad } & \multicolumn{2}{|l|}{ Fair } & \multicolumn{2}{|c|}{ Excellent } & \\
\hline & No. & $\%$ & No. & $\%$ & No. & $\%$ & \\
\hline Difficult visualization of the colon & 23 & 100 & 13 & 22.8 & - & - & $<.001^{* *}$ \\
\hline Canceled \& repeated colonoscopy & 19 & 82.6 & - & - & - & - & $<.001^{* *}$ \\
\hline Abdominal pain or discomfort & 4 & 17.4 & 57 & 100 & 39 & 97.5 & $<.001^{* *}$ \\
\hline Abdominal distention.(bloating) & 1 & 4.3 & 47 & 82.5 & 34 & 85 & $<.001^{* *}$ \\
\hline Tachycardia & 2 & 8.7 & 3 & 5.3 & 5 & 12.5 & .443 ns \\
\hline Cardiac dysrhythmias & - & - & 1 & 1.8 & - & - & $.573 \mathrm{~ns}$ \\
\hline Hypertension & - & - & 10 & 17.5 & 4 & 10 & $.081 \mathrm{~ns}$ \\
\hline Hypotension & 2 & 8.7 & 4 & 7.0 & 5 & 12.5 & $.652 \mathrm{~ns}$ \\
\hline Vomiting & - & - & 1 & 1.8 & 2 & 5.0 & .418 ns \\
\hline
\end{tabular}

$p<.001^{* *}$

\section{Discussion}

Based on the results of the present study, more than half of the patients at routine, video and both booklet \& video groups were males, while more than half of the patients in an educational booklet group were females. More than one third of patients at routine instructions, educational booklet, and preparation video groups and more than half of the patients at both video \& booklet group their ages ranging between $(30-50)$ years. Voiosu $(2013)^{[14]}$ in the same line with the study findings, reported that more than half of the patients of the study sample were male. While the mean age was 59.5 years (+13 years). Also, Shieh et al. $(2013)^{[15]}$ revealed that more than half of the patients in the education group and in the control group were men. The mean age of patients in the education group was $46.1 \pm 10.9$ years, and in the control group was $52.8 \pm 14.3$ years.

Regarding the patients' marital status, the majority of patients at the four study groups were married. This result was in the same line with van Jaarsveld et al. (2006), ${ }^{[16]}$ who revealed that married adults were more likely to participate in colorectal cancer screening colonoscopy than the non-married, and inviting both members of a couple together further increases screening uptake. The positive effect of marriage was as strong for women as men. 
Regarding education, one third of routine nursing instruction group and nursing educational booklet group of patients have secondary education level; while more than one third of preparation video and both video and booklet groups of patients were illiterate. The current study finding disagreed with Voiosu (2013), who mentioned that less than one third of patients had only attended elementary school (read and write), more than one third of patients were secondary school graduates, and more than one third of patients had received some form of high education.

Regarding occupation, more than one third of patients in the routine instructions, educational booklet and preparation video groups of patients were housewives, while more than one third of patients at both video and booklet group are employee.

Regarding residence the majority of patients in all four study groups were lived in rural areas. The current study findings disagreed with Henry (2015) ${ }^{[17]}$ who revealed that little is known about the effects of geographic factors, such as rural versus urban residence and travel time to colonoscopy providers, on risk-appropriate use of colorectal cancer (CRC) screening in the general population. More than half of the sample adhered to risk-appropriate CRC screening guidelines, with significant differences between urban and rural residents (68\% vs. 57\%, with $p<.001)$ across all familial risk groups. Rural residents were less likely than urban dwellers to be up-to-date with screening guidelines.

As regard the medical diagnosis, more than one quarter of patients at routine instructions and preparation video groups were diagnosed as ulcerative colitis and iron deficiency anemia. On the other hand more than one quarter of patients in educational booklet and both video \& booklet groups were diagnosed as ulcerative colitis and colorectal cancer. HabrGama et al. (2015) ${ }^{[18]}$ agreed with the finding of our study and mentioned that colonoscopy can be used to diagnose and evaluate the extent and severity of ulcerative colitis, which can be useful in guiding medical therapy and in the consideration of surveillance examinations. Intubation of the terminal ileum and biopsy can be useful in distinguishing ulcerative colitis from Crohn's disease; colonoscopy and sigmoidoscopy with biopsy are often used to assess histological improvement as a measure of the effectiveness of a medical treatment.

Also, Nolan (2011) ${ }^{[19]}$ reported that since anemia can result from a variety of causes (from inflammation in the colon to colon cancer), there are many optional screening tests that can be administered in attempt to discover the underlying condition. A colonoscopy procedure will determine whether a patient has pouches (diverticulum) or polyps that are causing bleeding or inflammation in the large intestine. Gastrointestinal bleeding or ulcer is another example of a condition that may cause significant blood loss in a patient diagnosed with anemia.

According to Zauber et al. (2012), ${ }^{[20]}$ who reported that screening for CRC in asymptomatic patients can reduce the incidence and mortality. In the United States, colonoscopy has become the most commonly used screening test. Adenomatous polyps are the most common neoplasm found during CRC screening. There is evidence that detection and removal of these cancer precursor lesions may prevent many cancers and reduce mortality.

The current study showed that more than one third of patients as in routine nursing instructions, pre colonoscopy preparation video and both video and booklet group, and more than half of the patients as in nursing educational booklet group were suffering from rectal bleeding. Also, one third of the patients (as in routine nursing instructions, nursing educational booklet and pre colonoscopy preparation video groups) and one half of the patients as in both video and booklet group perform therapeutic colonoscopy and tissue biopsies were taken.

This result from the researcher opinion is due to increase the number of patients diagnosed as ulcerative colitis, crohn's disease and colorectal cancer and rectal bleeding is the most common symptom for these diseases. The researcher opinion was supported by Nordqvist (2013) ${ }^{[21]}$ who reported that symptoms of ulcerative colitis include bloody diarrhea, which may be associated with crampy abdominal pain and sudden urgency to have a bowel movement. Loss of appetite, weight loss and fatigue are also common symptoms. In cases of severe bleeding, anemia may occur.

Also, American cancer society $(2015)^{[22]}$ reported that colorectal cancer may cause one or more of these symptoms as a change in bowel habits (such as diarrhea, constipation, or narrowing of the stool, that lasts for more than a few days), rectal bleeding, blood in the stool, which may cause dark stool, cramping or abdominal pain, weakness, fatigue and unexplained weight loss. In the case of lower gastrointestinal (GI) bleeding, colonoscopy can be useful to not only localize the site of bleeding but also as a potential for therapeutic intervention.

Warner (2014) ${ }^{[23]}$ was also in the same line and reported that, according to a study published in the scientific Journal of Gastroenterology, the risk of colorectal cancer among people with ulcerative colitis ranges from about $2 \%$ after 10 years of the disease $8 \%$ after 20 years to $18 \%$ after 30 years of the disease, and Mattar et al. (2011) ${ }^{[24]}$ which revealed that the 
crude annual incidence rate of colorectal cancer in ulcerative colitis ranges from approximately $0.06 \%$ to $0.16 \%$, with a relative risk of 1.0-2.75. The exact mechanism for this change is unknown; it may partly be explained by the more widespread use of maintenance therapy and surveillance colonoscopy.

The results of the current study showed that more than half of patients in routine instructions group have bad level of bowel cleanliness, more than two thirds of patients at preparation video group have fair level of bowel cleanliness, also, more than half of patients at educational booklet and both video \& booklet group have excellent level of bowel cleanliness. As regard to Boston bowel preparation scale, there is high statistically significant different in the cleaning level of the colon of four study groups of patients undergoing colonoscopy.

These results from the researcher's opinion were due to receiving the patients educational instructions about preparing the colon preparation before colonoscopy by using audiovisual aids as educational booklet and video.

Bastable et al. (2011) ${ }^{[25]}$ agreed with the researcher's opinion and reported that the instructional materials assist the nurse to deliver messages creatively and clearly during patient education. A multimedia approach for teaching helps learners to retain effectively what they learn, helps clarify abstract or complex concepts, adds variety to teaching-learning experience reinforces learning and potentially brings realism to the experience. It is well documented that the use of audiovisual aids facilitates learning. Therefore, nurses must look for ways to supplement their teaching with methods that help the learner to more easily acquire knowledge, attitudes, and skills.

The results of current study revealed that more than two thirds of patients at a routine instructions group and more than quarter of patients at pre-colonoscopy preparation video group had difficult visualization of the colon during colonoscopy and so, nearly half of these patients canceled the procedure and repeated colonoscopy was done for them. Chan et al. $(2011)^{[26]}$ agree with these findings which revealed that unfortunately, up to $20 \%-25 \%$ of all colonoscopies are reported to have an inadequate bowel preparation. The reasons for this range from patient-related variables such as compliance with preparation instructions and a variety of medical conditions that make bowel cleansing more difficult to unitspecific factors (e.g., extended wait times after scheduling of colonoscopy). Adverse consequences of ineffective bowel preparation include lower adenoma detection rates, longer procedural time, lower cecal intubation rates, increased electrocautery risk, and shorter intervals between examinations.

According to Zuccala $(2015)^{[27]}$ who mentioned that an im- properly prepared bowel increases cost related to repeating the procedure; and leads to dissatisfied patients. High quality bowel preparation is essential for a successful colonoscopy and involves dedication and persistence on the part of the patients. Adequate bowel preparation is associated with shorter procedure time and complete visualization of the entire colon (enabling a successful procedure).

Also, Hassan et al. (2013) ${ }^{[28]}$ reported that an adequate level of cleansing was critical for the efficacy of colonoscopy. Two key quality indicators of colonoscopy, cecal intubation rate and polyp detection rate, are associated with the quality of bowel cleansing. An inadequate level of bowel cleansing also results in further costs as the examination has to be re-scheduled or alternative investigations have to be organized. Furthermore, the discomfort and inconvenience of bowel preparation may affect the acceptability and uptake of colonoscopy in screening programs.

The present study illustrated that there was a statistical significant difference between four groups of patients undergoing colonoscopy related to difficult visualization of the colon, canceled and repeated colonoscopy. The best results (less incidence of problems and complications) was in the both video \& booklet group, then educational booklet group, then preparation video group, and finally routine instruction group.

Johnson et al. (2014) ${ }^{[29]}$ was in the same line with the present study which revealed that a patient education program administered by health care professionals increases patient compliance, improves quality, and decreases repeat examinations and costs. The use of both verbal and written instructions, compared with written instructions only, is an independent predictor of adequate bowel preparation quality. Educational tools such as booklets, information leaflets, animations, and visual aids should be standardized and validated, and should be effective across a range of health literacy and education levels. The use of a novel patient educational booklet on precolonoscopy preparation resulted in better bowel preparation quality scores than those achieved using conventional instructions.

The majority of the patients in all four groups of the study were complained from abdominal pain and discomfort. Weilan et al. $(2015)^{[30]}$ mentioned that Abdominal pain or distension developed after colonoscopy has been a common phenomenon in clinical practice. Progression has been made by replacing the insufflated air for good visualization of the colon, prevalence of these abdominal discomforts after colonoscopy vary from $14.6 \%$ to $48.5 \%$. Also, American Association of Gastrointestinal Endoscopy (2011) ${ }^{[10]}$ mentioned that the most commonly reported minor complications 
of colonoscopy are abdominal distension (bloating) (25\%) and abdominal pain and/or discomfort 5\% to $11 \%$. Appropriate techniques, such as avoiding and reducing endoscope looping and minimizing air insufflation should help reduce these symptoms.

Finally, it can be concluded that educating colonoscopy patient using different nursing educational methods as audiovisual aids is considered a corner stone in achieving accepted level of bowel cleanliness; decrease cost and early detect any abnormalities in the colon.

\section{Conclusion}

Based on the results of the present study, it can be concluded that:

- More than half of the patients in routine instructions group have a bad level of bowel cleanliness while more than two thirds of patients at preparation video group have a fair level of bowel cleanliness.

- More than half of the patients at educational booklet group have an excellent level of bowel cleanliness while more than two thirds of patients at preparation video group have a fair level of bowel cleanliness.

- More than half of the patients at both video \& booklet groups have an excellent level of bowel cleanliness while more than half of the patients in routine instructions group have a bad level of bowel cleanliness.

- The incidence of colonoscopy problems and complications in patients who had received both video \& booklet was less than patients who had received routine care except abdominal pain or discomfort and abdominal bloating.

\section{Recommendation}

- Relevant written and visual information to facilitate educating patients about proper preparation of the bowel before colonoscopy.

- Sufficient information about signs and symptoms of the potential complications and the importance for seeking rapid medical advice.

\section{ACKNOWLEDGeMENTS}

Praise to Allah, the Merciful, the Compassionate for all the countless gifts I have been offered. It is a pleasure for me to express my profound gratitude and appreciation to Dr. Mimi Mohammed Makkawy, for her kindness, genuine guidance and very keen supervision in revising every part of this paper. With considerable appreciation, I express my deepest gratitude to Dr. Zain Al-Abdeen Ahmed Sayed for his kind help, stimulating enthusiasm and unlimited help which were encouraging towards the accomplishment of this work. I am so grateful to Dr. Sahra Zaki Azer, for her valuable suggestions and close supervision. She generously offered her valuable time to guide me and answer all my questions. I would like to express my gratitude to all who helped me in fulfilling my responsibilities toward this work especially, the nursing members, patients and physicians in General Surgery Department, Internal Medicine Department, and Gastrointestinal Endoscopy Center at Assiut University Hospital for their cooperation and positive responses.

\section{CONFlicts of InTEREST Disclosure}

The authors declare that there is no conflict of interest.

\section{REFERENCES}

[1] Sherid M, Samo S, Sulaiman S. Complications of Colonoscopy, Colonoscopy and Colorectal Cancer Screening - Future Directions, Dr. Marco Bustamante (Ed.). 2013. Available from: http://www. intechopen. com/books/colonoscopy-and-c olorectal-cancer-screening-future-directions/comp lications-of-colonoscopy

[2] Peery AF, Dellon ES, Lund J. Burden of gastrointestinal disease in the United States. Gastroenterology Journal. 2012; 143: 117987. PMid:22885331 http://dx.doi.org/10.1053/j.gastro. 2012.08 .002

[3] Green D. Colonoscopy, Proctology Specialists. 2015. Available from: Proctologyspecialists.com/procedures/colonoscopy

[4] Rubin PH, Waye JD, Aisenberg J. Practical colonoscopy, 1st ed., Wiley Blackwell Company, Chapter 3 and 6. 2013. 135, 296 p.

[5] Soper NJ, Swanstrom LL, Eubanks WS. Endoscopic and Laparoscopic Surgery, 3rd ed., Lippincott Williams and Wilkins Company. Chapter 45. 2009. 448 p.

Published by Sciedu Press
[6] Rosenfeld G, Krygier D, Enns RA. The impact of patient education on the quality of inpatient bowel preparation for colonoscopy. Canadian Journal of Gastroenterology. 2010; 24: 543-6.

[7] Smeltzer SC, Bare BG, Hinkle JL, et al. Brunner \& Suddarth's textbook of medical- surgical nursing, Anatomy of digestive system, 11th ed., Lippincott Williams and Wilkins Company. 2008. 1136-1145 p.

[8] Calderwood A, Walker J. The Boston Bowel Preparation Scale Educational Program Overview. 2012.

[9] Zúñiga VL, Moreno-de-Vega V, Boix J. Preparation for colonoscopy: types of scales and cleaning products. Revista Espanola de Enfermedades Digestivas Journal (Madrid). 2012; 104(8): 426-431. http://dx.doi.org/10.4321/S1130-01082012000800006

[10] ASGE Standards of Practice Committee. Fisher DA, Maple JT, et al. Complications of colonoscopy. Gastrointest Endosc. 2011 Oct; 74(4): 745-752. PMid:21951473 http://dx.doi.org/10.1016/j.gie .2011 .07 .025

[11] Muma RD, Lyons BA. Patient Education: A Practical Approach, 2nd ed., Jones and Bartlett Company. 2012. 2, 12 p. 
[12] Muma RD, Lyons BA. Patient Education: A Practical Approach, 2nd ed., Jones and Bartlett Company. 2012. 84 p.

[13] Assiut university hospital statistical records. Internal medicine and Gastroendescopy center records. 2013. 335- 498 p.

[14] Voiosu T, Ratiu I, Voiosu A, et al. Time for individualized colonoscopy bowel- preparation regimens. A randomized controlled trial comparing sodium picosulphate and magnesium citrate versus 4liters split dose polyethylene glycol. Journal of Gastrointestinal Liver Disease. 2013; 22(2): 129-134.

[15] Shieh TY, Chen MJ, Chang CW, et al. Effect of Physician-Delivered Patient Education on the Quality of Bowel Preparation for Screening Colonoscopy. Gastroenterology Research and Practice. 2013 PMid:24454341 http://dx.doi.org/10.1155/2013/570180

[16] Van Jaarsveld CH, Miles A, Edwards R, et al. Marriage and cancer prevention: does marital status and inviting both spouses together influence colorectal cancer screening participation? Journal Med Screen. 2006; 13(4): 172-6. Available from: http://www.ncbi.n Im.nih.gov/pubmed/17217605 PMid:17217605

[17] Henry KA. Rural vs. urban residence affects risk-appropriate colorectal cancer screening. 2015. Available from: http://www . researchgate.net/publication/2338782 96_Rural_vs_Urban_Residence_Affects_RiskAppropriat e_Colorectal_Cancer_Screening

[18] Habr-Gama A, Arruda Alves PR, Rex DK. Indications and contraindications of colonoscopy. 2015. Available from: http://www.gast rohep. com/ebooks/ebook . asp?book=1405120800\&id=2

[19] Nolan DM. Anemia. 2011. Available from: http://www . colono scopy.com/conditions/anemia

[20] Zauber AG, Winawer SJ, O’Brien MJ. Colonoscopic Polypectomy and long-term prevention of colorectal-cancer deaths. New England Journal of Medicine. 2012; 366:687-696. PMid:22356322 http://dx.doi.org/10.1056/NEJMoa1100370

[21] Nordqvist C. What is ulcerative colitis? 2013. Available from: http: //www.medicalnewstoday.com/articles/163772.php

[22] American Cancer Society. Colorectal cancer prevention and early detection. 2015. Available from: http: //www. cancer.org/cancer/colonandrectumcancer/m oreinformation/colonandrectumcancerearlydetection/ colorectal-cancer-early-detection-symptoms-of-crc

[23] Warner J. Ulcerative Colitis: The Importance of Screening for Colorectal Cancer. 2014. Available from: http: //www.everydayhealth.com/hs/ulcerative-colitis-tre atment-management/colorectal-cancer-screening/

[24] Mattar MC, Lough D, pishvaian MJ, et al. Current Management of Inflammatory Bowel Disease and Colorectal Cancer. Gastrointestinal Cancer Research. 2011; 4(2): 53-61. PMid:21673876

[25] Bastable SB, Gramet P, Jacobs D, et al. Health Professional as Educator: Principles of Teaching and Learning, 5th ed., Jones and Bastable publisher Company. 2011. 463 p.

[26] Chan WK, Saravanan A, Manikam J. Appointment waiting times and education level influence the quality of bowel preparation in adult patients undergoing colonoscopy. BMC Gastroenterology Journal. 2011; 11: 86. PMid:21798022 http://dx.doi.org/10.1186/1 471-230X-11-86

[27] Zuccala B. Improving the quality of bowel preparation for colonoscopies. 2015. Available from: http: //www .endonurse.com/articles/2015/07/improving -the-quality-of-bowel-preps-for-colonosc.aspx

[28] Hassan C, Bretthauer M, Kaminski MF, et al. Bowel preparation for colonoscopy: European Society of Gastrointestinal Endoscopy (ESGE) Guidelines. Endoscopy Journal. 2013; 45: 142-150. PMid:23335011 http://dx.doi.org/10.1055/s-0032-13261 86

[29] Johnson DA, Barkun AN, Cohen LB, et al. Optimizing Adequacy of Bowel Cleansing for Colonoscopy: Recommendations From the US Multi-Society Task Force on Colorectal Cancer. American Journal of Gastroenterology. 2014. http://dx.doi.org/10.1053/j .gastro.2014.07.002

[30] Weilan W, Chen Y, Yao Y, et al. Transcutaneous electric acupoint stimulation at Jiaji points reduce abdominal pain after colonoscopy: a randomized controlled trial. International Journal of Clinical Experience. 2015; 8(4): 5972-5977.

[31] American Association of Gastrointestinal Endoscopy. Gastrointestinal Endoscopy Journal. 2011; 74(4): 745-752. PMid:21951473 http://dx.doi.org/10.1016/j.gie.2011.07.025 